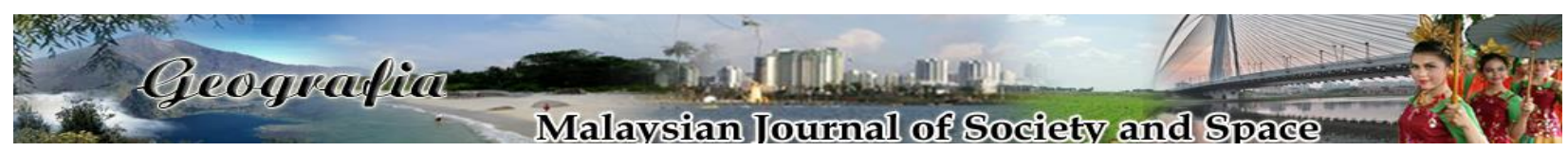

\title{
Escapism and motivation: Understanding K-pop fans well-being and identity
}

\author{
Nur Ayuni Mohd Jenol, Nur Hafeeza Ahmad Pazil \\ School of Social Sciences, Universiti Sains Malaysia \\ Correspondence: Nur Hafeeza Ahmad Pazil (email: hafeezapazil@usm.my)
}

Received: 01 October 2020; Accepted: 24 November 2020; Published: 29 November 2020

\begin{abstract}
K-pop is a relatively new genre but its fanbase has grown massively in Malaysia for the past few decades. It is also evident that the daily lives of Malaysians have incorporated Korean culture in various social aspects. Thus, this study seeks to explore the well-being of local K-pop fans by underlining the objective to understand the meaning of being a K-pop fan. In order to describe and analyse the social nuances of the well-being being a K-pop fan, several concepts from sociology as well as fan studies were plotted to assist this research such as para-social relationship, identity and social identity, the concept of meaning as well as participatory culture. A qualitative approach was employed by using participant observation and semi-structured indepth interviews to get into the experiences, views, values, and lifestyles of K-pop fans. Participant observation was conducted in K-pop concerts and fan events to observe fan practices. As for the semi-structured in-depth interview, a total number of eight participants were selected to provide an understanding of K-pop fan's well-being through their experiences and feelings. This study concludes that being a K-pop fan carries its special meaning that transcends a fan of a music genre. It varies from providing a platform for escapism as well as emotional and motivational support through a para-social relationship. Although fan and idol is usually seen as one-sided relationship, it has benefitted the fan's well-being in some way. This study also proves that the fans can also be seen as active producers and content creators which contradict to the notion of fan as a passive entity.
\end{abstract}

Keywords: escapism, identity, K-pop fans, motivation, para-social relationship, well-being

\section{Introduction}

Notably, the Korean wave or Hallyu wave has flourished worldwide since a decade ago (Joyce \& Pacis, 2012). Korean wave is specifically referred to as the Korean culture that consists of the language, dramas and movies, food, music, and other cultural products. Korean-pop or familiarly known as K-pop, is the most phenomenal and impactful out of all. A local radio channel in Malaysia, Hitz FM together with Korean Tourist Organization introduced a new K-pop talent 
show program. This show later got a high rating and this validated the public acceptance and demand for K-pop music (Ariffin, Othman, Abdullah, \& Wan Mohammad Arif, 2013). Besides that, ASTRO also provides KBS World Channel - a channel that broadcasts Korean dramas, music and reality shows to satisfy the desire of audiences towards Korean entertainment (Ni, 2019). This Korean wave took social media by storm as well as Malaysian KPOP Fans Facebook page has also been set up to discuss and interact with Korean fans nationwide (Dzul, 2016). The omnipresence of K-pop on various media platforms in Malaysia has made it easy for locals to gain access to this genre. Hence, it is beneficial to study the social nuances of local K-pop fans. It is also evident that the daily lives of Malaysians have incorporate Korean culture in various social aspects.

Being a fan is not merely a leisure activity but also create a new form of culture called participatory culture. Participatory culture means that fans not only consume media by listening and watching but also use selected media content to recreate and reproduce their content. Fans usually communicated through the sharing of physical text or art as well as gathering in fan conventions and fan meetings. As technology continues to evolve, fan communities increasingly prevalent across nationality, ethnicity and internet based (Groene \& Hettinger, 2016). Accordingly, fan studies have become an important topic for academia in not only the media and communication field. Scholars from various academic disciplines have been interested in fan studies range from Economics, Arts, Psychology, as well as Anthropology and Sociology (Tinaliga, 2018). Most of the fans that are usually rooted in a particular music genre such as punk, heavy metal, indie, and jazz.

The invention of Guttenberg's printing press in the middle of the 15th century has brought the acknowledgment of the influence that mass media bring to audiences (Abida \& Rana Eijaz, 2011). Although books were only available for the rich, printing became cheaper as less wealthy members of society were able to gain access to this luxury item at that time. Society realized that the ability to read has become obligatory and they began to believe that all members should be educated to read (Monika \& Iveta, 2016). As literacy began to rise as well as the types of media and information people could be exposed to, a dedicated individual showing devotion to any object that typically accessible through the traditional media such as books, magazines, comics, TV, and radio also emerged (Rahim, 2019). For example, fans of Sherlock Holmes by Arthur Conan gained the public's attention and adoration during the late Victorian era (Donley et al., 2017). They proclaimed themselves as the members of the first fandom ever existed. While in the early to mid-twentieth century, fans of science fiction began forming clubs and holding conventions to discuss their shared interest. One of the earliest conventions was the World Science Fiction Convention or Worldcon, which was first, held in 1939 and has continued annually. It was noted that there is no other popular culture phenomenon that has shown the depth and breadth of fan activity. Aside from attending such conventions, fans also created the first Star Trek zine, a fan-made magazine called Spockanalia, in 1967 (Jindra, 2017). This portrayed that being a fan is not simply consuming. Rather, fans engage with the media as well as among other fans. Although K-pop is a relatively new genre but its fanbase has grown massively in Malaysia for the past few decades. Besides, there are some concerns revolved around the subject of a fan as it often considered to be non-intellectual, simple, and unimportant in academia (Rhee, Wong, \& Kim, 2016). This research helps to clarify the importance of this phenomenon socially. It seeks to explore on how the well-being of an individual interrelated with being a K-pop fan. Thus, the objective that has guided this research process is to understand the meaning of being a K-pop fan. 


\section{Literature review}

The internet has made it possible and manifests identity formation through online spaces. These online identity constructions resulted from shared interest with other people to demonstrate the way online and offline identities are interrelated (Manago, 2015). The sociological approach of identity does not address the psychological or cognitive processes of identity, but rather how identity is presented and re-presented within a social situation. Symbolic Interactionism is a classic concern regarding the construction of identity within an Anthropology and Sociology context. Mead (1934) said that the existence in a community comes before individual consciousness as he believed that "society shapes self, self shapes social behaviour" (p.13). Goffman (1959) presents a sociological perspective that interested in understanding human interactions. He suggested that when an individual is in the physical space with other people, he or she will seek to control the impression that others form him or her. Being a fan is one of the identities that an individual play in society.

It is also believed that individuals act by a shared understanding of meaning within their social context. Meaning is to gain and learn via interactions between people and arise because of the exchange of symbols in social groups (Anwar, 2018). Thus, the meaning is a framework that helps to understand how society is preserved and created through repeated interactions between individuals. As the studies of the online community increasing, the concept of the online community has also become important and more accepted as a social construct. Lin and Tong (2008) in their research suggest that South Korea's portrayal of a modern capitalist country and its consumerist culture through Korean wave such as K-pop has somewhat affected the K-pop fan's identity. It has also been proved that there is an interplay of forces between fan's self and their interest towards K-pop (Ni, 2019).

Media produces images, symbols, and codes that offer a new reality for people (Baudrillard, 1983). Appadurai (1996) points out that it creates a sort of a utopian community. According to Batoul and Fawwaz (2017), K-pop fans not only learned the Korean language but also understand the exclusive and particular terms that are only understood within K-pop fan communities. Seoulbeats (2012) noted that South Korea is one of the few countries where the use of celebrities in commercials surpasses $50 \%$ and the advertisement industry is flooded with idols. This leads to fans who are intensely and neurotically involved with their favourite celebrity (Collisson, Browne, McCutcheon, Britt, \& Browne, 2018). They suggest that being a fan is like being in a recognized religion, it helps fan having a higher level of subjective well-being. Ryff (1989) also points out that being a part of the fan community helps an individual to strive for personal growth and development. Moreover, it is also important to bring into attention the established theory of fan-celebrity relationship by Horton and Wohl (1956) - para-social relationship. In the field of Anthropology and Sociology, there are plenty of researchers that are concerned with the ways celebrities as icons affect the culture and how individuals view those celebrities (Stever, 2009). Caughey (1984) also mentioned that "the basis of most fan relationships is not an aesthetic appreciation but a social relationship. Fans have attachments to unmet media figures that are analogous to and in many ways directly parallel to actual social relationships" (p. 40). 


\section{Method and study area}

A systematic and thorough analysis of the methodology procedure was made to achieve the objective of this research. In particular, researchers used a qualitative approach as generally it was developed in the social sciences field to enable researchers to study social and cultural phenomenon (Newman, 2013). This study regards fan as a unit of analysis which researcher got into each of their experiences, views, values and lifestyles as a K-pop fan. An interpretative framework which concerned with meaning and seeks to understand people's behaviour is also been used in this research.

\section{Participants}

This research used purposive sampling as the objective required researchers' judgment by choosing the members of the population to participate in the study (Dudovskiy, 2012). Purposive sampling is one of the most common sampling techniques in which a group of participants is preselected by the researcher according to relevant criteria regarding the research subject (Dudovskiy, 2012). In this study, researchers were not looking merely for a K-pop fan to participate but those who are actively involved in fans' activities such as joining the fan event, going to the concert, collecting albums, or doing songs and dance cover. This requires us to use knowledge and judgments to identify these people to satisfy the needs of this study. Snowball sampling was also used as there were a few participants that are introduced by other participants. The sample for this research study was eight K-pop fans. This sample intentionally consisted of participants that age around 15 to 30 years old which are regarded as young adults according to the National Youth Development Policy of Malaysia (2019). The purpose of focusing on one group of participants who share a similar age group and background is to get the representative findings for this particular age group.

Table 1. Demographic Background of Participants

\begin{tabular}{llccc}
\hline \multicolumn{1}{c}{ Name } & Age & $\begin{array}{c}\text { Relationship } \\
\text { Status }\end{array}$ & Hometown & University \\
\hline Athirah & 24 & Single & Pulau Pinang & University A \\
Mimi & 24 & In a relationship & Kedah & University A \\
Lana & 23 & In a relationship & Perak & University A \\
Sabrina & 23 & Single & Kuala Lumpur & University B \\
Sonia & 23 & Single & Kuala Lumpur & University C \\
Gina & 25 & Married & Selangor & - \\
Alyani & 24 & Single & Kelantan & University D \\
Candy & 24 & Single & Perak & University E \\
\hline
\end{tabular}

The demographic background of participants is illustrated in detail in Table 1. Pseudonyms were used for the names of participants and universities to maintain confidentiality. Almost all of the participants are single with two of them are in a relationship and only one participant is reportedly married. Other participants are students in local universities and most of them are 23 and 24 years old. 


\section{Data Collection}

The data collection techniques in this research study are participant observation and semistructured in-depth interviews. There were two phases in the data collection process in this study which are 1) the first phase: participant observation and 2) the second phase: semi-structured indepth interview. In the first phase, the data collection was conducted in January 2020. While the second phase of data collection was conducted in February 2020 and completed in the middle of March 2020.

\section{a. Participant observation}

In January 2020, the researchers' presence in WINNER's - a K-pop boy group concert in Axiata Bukit Jalil and fan event at KL Sentral has allowed researchers to participate and observe fan's practices during the event in which thousands of the attendees were K-pop fans. Kuala Lumpur was chosen as the geographical area in which the study was conducted because most young people especially in the capital city have demonstrated an increasingly high level of involvement with celebrities. This is because of places such as concert stadium, airport, and malls that are located in Kuala Lumpur is a good place to collect K-pop celebrities-related data as most of the meet and greet session, media interview, album launching, movie promotions or road tour are usually held in the main city like Kuala Lumpur. It provides an alternative for researchers to engage with targeted age and group of participants who enjoy such leisure and entertainment. According to Um (2014), the observation method is extremely useful and essential in the sense that this research approach allows exploring the dynamics of groups of people specifically in the life of fans. A K-pop concert and fan event in Kuala Lumpur was chosen as the location for observation, as a concert is the best place where most K-pop fans are gathered. Besides that, concerts and fan event also provided opportunities for the fans to share and display their passion for K-pop. Fans' performativity at the concert and fan event in terms of language, activities, and interactions with fellow fans has been observed. The direct experience helped researchers to gain insight into the fan's behaviour. In addition to that, researcher also used field notes and photographs that were taken during the observation as research data. Under no circumstances did these instruments cause disturbance or intrusion to any of the fans.

\section{b. Semi-structured in-depth interview}

The second phase which is the semi-structured in-depth interview started in February 2020 until the middle of March 2020. This data collection took about an hour to two hours to be completed for each participant. It was our goal to gain a specific and critical perspective to answer both of the research questions. Interviewing selected individuals is a very important method often used by qualitative researchers. The rationale is to enable to find out what is on the participant's mind, what did they think, and how they feel about something (Newman, 2013). A total number of eight participants were selected as previously mentioned. Participants in this research were selected through the K-pop-related contents on their public social media accounts which is Instagram. Researchers contacted them via direct message and once they were willing to participate, the place and time of the meeting were decided. Most of the interviews were conducted in public places such as at K-pop fan event as they preferred the sense of security and comfort in the public space. However, due to practical constraints such as the COVID-19 pandemic, some of the interviews conducted via phone call. Concerning the ethical 
considerations regarding fans who partook in the research, researchers obtained their informed consent before audiotaping interviews. The participants were also given the option to skip or refuse to answer questions and could withdraw from the study at any time. The recorded audio and photographs are kept confidential and will be destroyed after five years of this study. Some questions were prepared based on the literature to answer the research objectives, but there are also a few additional questions made during the interviews that are relevant for the findings.

\section{Data analysis}

Data analysis involves making sense of the participants' input and looking for patterns and connecting them (Newman, 2013).. In this study, researchers used thematic analysis to explore the findings. Thematic analysis is a good approach to find out about people's experiences and values from a set of qualitative data (Caulfield, 2020). Thematic analysis was employed in this research by six steps which are 1) familiarization of the transcripts, 2) coding and identifying themes, 3) generating themes, 4) reviewing themes, 5) defining and naming themes and 6) writing up and relate to the sociological insights based on previous studies. After completing the data collection, researchers listen to the recorded audio and manually transcribed every eight interviews. Upon transcribing the responses, the recurrent themes by participants were highlighted and jotted down. The analysis in this study stems from data collected during the interview. However, the findings were presented and described along with the quotes from the interviews as well as the relevant data from the participant observation. Researchers also revisited the highlights to prevent missing significant or interpreted the data in different ways. Once assured with the findings, the codes were related with the anthropological and sociological concepts as well as previous studies.

\section{Results and discussion}

\section{K-pop as a form of escapism}

The need to belong or a sense of belonging is an innate human nature. However, an individual also motivated to break away from concerns over their social situations as society places many strains throughout their daily lives. Baudrillard (1983) has claimed that media produces images, symbols, and codes that offer a new reality in which "the fact becomes fiction and TV, becomes reality" (p. 334). In the case of Korean wave, media is undoubtedly responsible for its massive popularity. At the same time, it also creates an environment of escapism for fans (Ko et al., 2014). Fans can be very engaging with their fan activities. This is said by the participants in this research and one of them mentioned that:

(GINA) Sometimes when I feel tired, I do not know what to do or I do not feel like talking to people, I will listen or watch K-pop as it is the solution. I would watch the videos. At the end of the day, I would watch. After got back to class, feeling exhausted also I must watch them. More like a reward to me after a long or hard time.

According to Gina, fans typically feel compelled to follow every single update of their favourite idols. For example, fans would binge-watch shows that featured their idols from music 
videos, live streaming, interviews, fan cams, or dance practice. As been shared by other participants as well, they would also attend concerts if possible, join fan-event, purchase merchandise, making fan arts, streaming songs, copying idols style or look and even adopt their mannerisms. Furthermore, South Korea is one of the countries where the use of celebrities in commercials surpasses $50 \%$ and the advertisement industry is flooded with idols (Seoulbeats, 2012). The fact that idols appear in almost all forms of media such as social media, TV dramas, variety shows, commercials, movies, or even musicals makes it easier for fans to become more attached. Researchers also have noticed the presence of K-pop idols in local commercials and advertisements targeting the Malaysian audience are nothing new. The latest one for example is Rain and Siti Nurhaliza's Cuckoo commercial as the brand ambassador (MyMetro, 2020).

These experiences serve and allow fans to break away from unwanted social realities even if it is temporary. Although fans may not know idols personally and are fully aware of that, it creates a strong personal bond and attachment. Taking into consideration, the sheer amount of consumable content also makes it easy to be immersed for hours. The concept of para-social relationship is relevant to describe this phenomenon of fan and idol relationship. As previously mentioned, para-social relationship is described as a one-sided interaction and relationship attempt between fan and the media figures such as celebrities or fictional characters. Although it is one-sided, it is significant and proves that the $\mathrm{K}$-pop fan transcends musical discussion.

Besides that, Ko et al. (2014) also have claimed that fans describe the experiences being a fan is like a 'reward' to them. Thus, researchers believe that escapism provides fans a more desirable state of being than the one presently experienced by them or the reality. MadridMorales and Lovric (2015) study on K-Pop fandom in Spain and Latin America draws attention when they have suggested that K-pop provides a fantasy that allows fans an appealing escape. As noted by them, fan's preferences for a virtual environment in cyberspace may result from the despair they are facing in the real world. This phenomenon can also be seen among the participants in this research:

(ALYANI) Yes. When life gets hard, I feel like I need something to entertain me. I want to forget about my problems even for a while. It is effective. When you are going to a concert, the feeling that you are living in that moment is the best. You forget about what is happening outside of the stadium. It is you and them (your idols). Yes, I feel much better. But sometimes sad when it is over. The fact that I need to face reality.

Alyani among other participants mentioned that they feel sad when they need to face reality. They even suggested that sometimes they prefer virtual life over real life. Previous studies also have illustrated that the emergence of the internet has somewhat blurred lines between life in online spaces and the real world. Appadurai (1996) in particular has argued that the internet is capable to construct "imagined worlds that are chimerical, aesthetic, even fantastic objects, particularly if have been assessed by the criteria of some other perspective, some other imagined world" (p. 35). This phenomenon can be seen through the participant observation when researchers noticed that a more distinct and apparent performativity of K-pop fans. Most fan clubs regularly hold fan events, where members assemble and bond together by watching videos of their idols, play games, dance cover, and celebrating idols' events. Fans with social capital receive recognition from other fans because of their influence. During our observation at the concert as well, researchers began to recognise some of 'popular' fans. There are fanart makers 
who sell their self-made banners, photocards, and drawings while waiting for the concert to start. Some even give their stuffs for free. Besides that, there was also a group of fans in which most of them are dancers, perform their dance cover outside of the stadium while other fans chanting for them. Figure 1 below shows some of the photos from the fan event which were held in KL Sentral during the first phase of data collection.
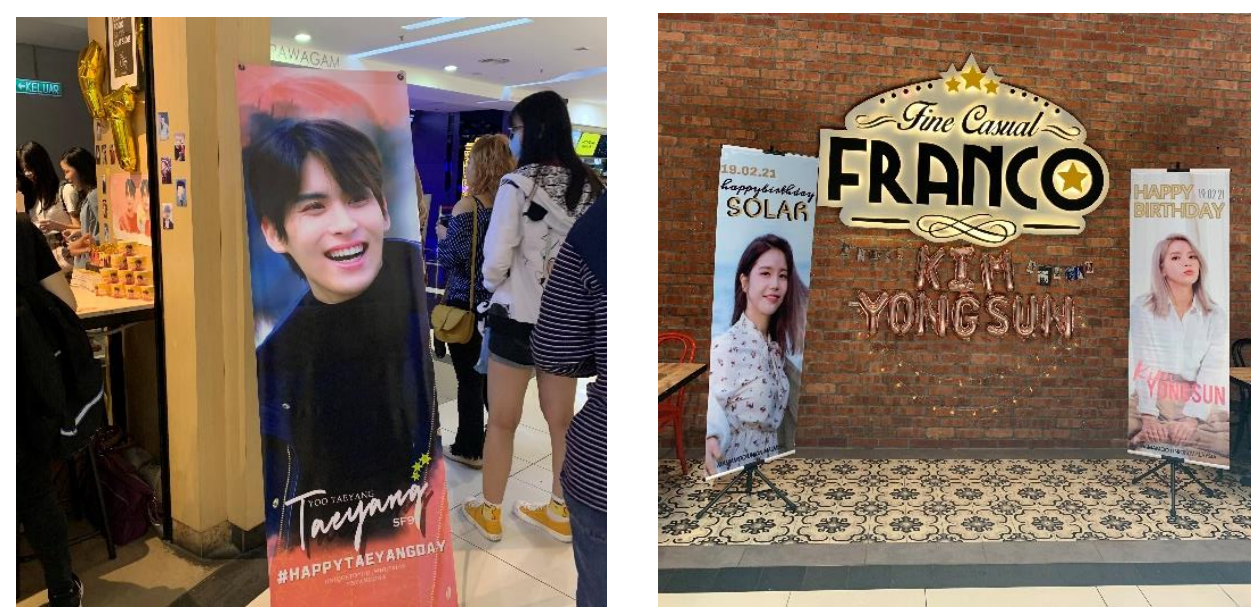

Figure 1. Fan Events at KL Sentral

Overall, these findings have led researchers to the argument that being a fan is a form of escapism for an individual in order to maintain their well-being. The para-social relationship that fans have with their favourite idols offer fans a new 'reality' that is more preferable. It is also important to highlight that fans have been provided with a wide range of tools to escape from unwanted realities. The blooming of diverse pop culture on the borderless internet somehow making a genre like K-pop is being able to serve a means of escapism for fans. Besides that, it is evident that the blurred lines between life in online spaces and the real world have resulted in the fans having their own identity, in a virtual community.

\section{Idolizing the idol: Cinderella story}

Researchers believed that it is important to also reveal the psychosocial meaning of being K-pop fans. Based on the data in this research, one of the recurrent themes that has emerged is being a K-pop fan facilitates fan's personal growth. According to Ryff (1989), being part of a fan community helps an individual to strive for personal growth and development. Contrary to that, Schultze et al. (1991) have argued that considering the great amount of time and money are spent on fandom activities, fan's indulgence may impair their academic, intellectual performance as well as identity and emotional development. This means that much uncertainty still exists in academia regarding this issue. While in this study, researchers figure out that being K-pop fans is indeed help individual with their well-being especially in terms of emotional struggles and as motivation in life. Aforementioned, fans are motivated to break away from concerns over their social situations as society places many strains on individuals throughout their daily lives. For them, idols can provide a sort of inspiration and solution to their problems. Athirah shared her amazement and adoration towards idols' behaviour by saying that: 
(ATHIRAH) Most of the time he (Yeseop from BEAST) would give me wise words to live by. There is this one time when fandoms were fighting, he made such a wise statement, I don't really remember what he said exactly but I remember how it impacted me as well as other fans until both fandoms reconcile. I believe that he used his power for a good cause.

Based on the quote above, it shows that idols' behaviour is important for fans as they do not only see them as performers but also take them as role-models. K-pop has a reputation as a competitive industry where young Korean boys and girls are trained often in tough conditions and waiting for years to become stars. Some even label these idols "to be programmed to entertain". In addition to that, not all trainees can make it. Once they debut, idols are forced to give up their ordinary life. This includes long hours of training, diet restrictions, gruelling gym routines, and for some, no dating and mobile phones (Soheili, 2019). Their behaviours are also closely monitored by the manager and their companies. Aware of this, some participants admired by the "Cinderella" stories of her favourite idols, WINNER. Other participants also told me that they are motivated to work hard either for their academic and career success or life in general by watching their idols. Idols are seen as the source of their motivation and making fans want to have a dream and live a fuller life. Besides that, participants also shared that idols also provide encouragement and assurances through their songs and the mindful lyrics.

Although K-pop is famous for its catchiness, funky appearance, and extravagant music videos but not all idols follow such format. Talking to the participants, researchers have realized that K-pop fans also appreciate slow and chill songs. Gina named a song - Breathe, as an example. It is a song that had been written by the late Jonghyun from SHINee who committed suicide in 2017 due to depression. It is speculated that the song is a cry for help from Jonghyun. It is about mental illness and it assures people especially fans who going through the same thing. Once again, this research findings are along with the concept of para-social relations. The relationship between fan and idol mimics the real relationships in the mind of the fan as it gives fan a sort of comfort and consolation dealing with hard times.

Heng (2019) points out how ARMY, BTS's fandom holds extraordinary communal solidarity. Fans with a desire to change their personal level in some way may affect social change. At this point, fans are not just consumers of popular music but being a fan has also driven positive force in them for a good cause. This can be seen when fandoms engaging in charity and humanitarian activities (Murphy, 2020) or even voicing their opinions on political agendas through fandom (BBC, 2020). Fans not only consume media by listening and watching they also inspired to get involve in fanworks like fan fiction, fan art, dance cover, songs cover, or even fan-event. In other words, fans also can be seen as active producers and as a part of the participatory culture (Jenkins, 1992). Based on both participant observation and interviews, these are some of the common practices among K-pop fans. Some fans even making a living or at least some extra income from their work. Several fan artists accept commissions through social media or have set up stores, like one of the participants, Sabrina.

SABRINA: It can be considered that I found my talent after I become a K-pop fan. Sometimes you never know what you can do. Before this, I do not know my passion, and which tracks that I am going to pursue. But with this kind of passion I got to improve myself, choose the track that suits me. It gives me the motivation to keep going on. 
Asides from Sabrina, other participants in this research also have revealed their talent in making K-pop-related arts and media content. For instance, Athirah is currently busy with editing and compiling videos of P.O from Block B in variety shows. Another participant, Sonia, is one of the admins that organize important fan events. She said that by involving in such fanactivities help her to gain her confidence to talk and communicate in public. While another participant, Gina, is a writer cum journalist for a living but often post K-pop songs cover on her social media. Candy, who is a student of Computer Sciences, occasionally making K-pop idols' VR photo card for her fellow K-pop fans. It is important to highlight the significant role idols bring in the life of fans. Idols share everything from the mundane to the awe-inspiring to connect with their fans. The parasocial relationship has made it possible for an individual to unleash and improve their potentials.

\section{Conclusion}

This study particularly has offered some important insights into the field by showing that a fan is not a passive entity. The para-social relationship that exists between fan and idol, even though it is one-sided relationship, has benefitted the fan specifically of their well-being. Commitment and attachment as part of the fandom community give a meaningful sense of self and intimacy. Therefore, the findings proved that K-pop fan, as part of the fandom community does not exist in a vacuum. Being a K-pop fan carries its own meaning that transcends a fan of a music genre. This study also revealed the meaning of being a K-pop fan not only due to their enthusiasm towards idols but also providing a better state of life through a platform for escapism. Besides that, being a K-pop fan also associated with fans' mental and emotional attachment with idols through a para-social relationship. In the case of Korean wave, the media is undoubtedly responsible for its massive popularity but at the same time, it also creates an environment of escapism for fans as shown in this study. Fan experiences serve as a mean to allow the fan to break away from unwanted social realities even if it is temporary. Although fans may not know idols personally and are fully aware of that, it creates a strong personal bond and attachment known as a para-social relationship. Besides fan-idol relationships, fans also managed to create a family-like relationship through fandom membership. Researchers also brought into attention how fandom holds extraordinary communal solidarity. Fan's desire to change on a personal level in some way affects social change. Researchers firmly believe that fan is not just consumer of popular music but being a fan has also driven positive force and well-being in themselves.

\section{Acknowledgement}

The researchers humbly acknowledge the contribution of the participants in this research for their time and effort to help with this research.

\section{References}

Abida, E., \& Rana Eijaz, A. (2011). Challenges of Media Globalization for Developing Countries. International Journal of Business and Social Science, 2(18), 100-106.

Anwar, C. R. (2018). Mahasiswa dan K-pop (Studi Interaksi Simbolik K-popers di Makassar). Jurnal Ilmu Komunikasi UPN Veteran Jatim, 1(1: Komunikasi dan Budaya Urban). 
Appadurai, A. (1996). Modernity at Large: Cultural Dimensions of Globalization. Minnesota: University of Minnesota Press.

Ariffin, Z. Z., Othman, K., Abdullah, R. T., \& Wan Mohammad Arif, W. N. A. (2013). Analyzing the Dimension of Korean Popular Culture Among Malaysian Adolescent. 5th International Conference on Humanities and Social Sciences, (August 2014), 11-35. Retrieved from http://www.libarts-conference.psu.ac.th/proceedings/Proceedings5/ proceedings5/CD-Proceedings5/1.2-Analyzing the Dimension of Korean Popular Culture Among Malaysian Adolescent.pdf

Batoul, T., \& Fawwaz, A.-H. (2017). The Influence of the Korean Wave on the Language of International Fans: Case Study of Algerian Fans. Sino-US English Teaching, 14(10), 598626. https://doi.org/10.17265/1539-8072/2017.10.004

Baudrillard, J. (1983). In the Shadow of the Silent Majority. New York: Semiotext.

BBC. (2020). BTS Black Lives Matter: Fans Match Band's \$1M Donation. BBC News. Retrieved from https://www.bbc.com/news/world-asia-52960617

Caughey, J. (1984). Imaginary Social Worlds. Lincoln: University of Nebraska Press.

Caulfield, J. (2020). How To Do Thematic Analysis. Retrieved from Scribbr website: https://www.scribbr.com/methodology/thematic-analysis/

Collisson, B., Browne, B. L., McCutcheon, L. E., Britt, R., \& Browne, A. M. (2018). The interpersonal beginnings of fandom: The relation between attachment style, trust, and the admiration of celebrities. Interpersona, 12(1), 23-33. https://doi.org/10.5964/ijpr.v12i1.282

Donley, K. M., Sayers, D. L., Morley, C., Desmond, S., Sydney, S., Roberts, C., ... Holmes, S. (2017). Early Sherlockian scholarship : Non / fiction at play. 23(Note 1), 1-19.

Dudovskiy, J. (2012). Purposive Sampling. Retrieved from Research Methodology.net website: http://research-methodology.net/sampling-in-primary-data-collection/purposive-sampling/ Hume,

Dzul, Z. (2016, November 28). Korean Wave's Here to Stay. New Straits Times. Retrieved from https://www.nst.com.my/news/2016/11/192393/korean-waves-here-stay

Goffman, E. (1959). The Presentation of Self in Everyday Life. In The Presentation of Self in Everyday Life. Oxford, England: Doubleday.

Horton, D., \& Wohl, R. R. (1956). Mass Communication and Para-social Interaction; Observations On Intimacy at a Distance. Psychiatry, 19(3), 215-229. https://doi.org/ 10.1080/00332747.1956.11023049

Jenkins, H. (1992). Textual Poachers: Television Fans \& Participatory Culture. https://doi.org/10.1017/CBO9781107415324.004

Jindra, M. (2017). It's About Faith In Our Future. Religion and Popular Culture in America, $223-241$.

Joyce, J., \& Pacis, C. (2012). Popping the K-Pop Bubble: a Study on the World of K-Pop Fandom As a Subculture. University of the Philippines Diliman.

Ko, N. C., Kim, J. N., No, S. I., \& Simoes, R. G. (2014). The Korean wave Hallyu in looking at escapism in Peruvian society. Perspectives on Global Development and Technology, 13(3), 332-346. https://doi.org/10.1163/15691497-12341305

Lin, A., \& Tong, A. (2008). Re-Imagining a Cosmopolitan 'Asian Us': Asian Modern Femininities. In East Asian Pop Culture: Analysing the Korean Wave (pp. 91-125). Hong Kong University Press.

Manago, A. M. (2015). Media and the Development of Identity. Emerging Trends in the Social and Behavioral Sciences, 1-14. https://doi.org/10.1002/9781118900772.etrds0212 
Mead, G. H. (1934). Mind, Self, and Society from the Standpoint of a Social Behaviorist. In Mind, Self, and Society from the Standpoint of a Social Behaviorist. University of Chicago Press: Chicago.

Ministry of Youth and Sports Malaysia. (2019). National Youth Development Policy..

Monika, B. M., \& Iveta, J. M. (2016). The Beginning of The Fan movement: Brief History of the First Fandoms. Palacky University Olomouc.

Murphy, E. (2020). How BTS Fans Utilized Social Media to Help Others. Showbiz Cheat Sheet. Retrieved from https://www.cheatsheet.com/entertainment/bts-army-social-media-recordsmark-millar-australian-wildfires-james-corden-ashton-kutcher.html/

Newman, L. (2013). Social Research Methods: Pearson New International Edition : Qualitative and Quantitative Approaches. Harlow: Pearson Education Limited.

Ni, G. X. (2019). A Qualitative Study on The Soft Power of Korean Popular Culture on Consumer Behaviour in Malaysia. Universiti Tunku Abdul Rahman.

Rahim, A. A. (2019). Online Fandom: Social Identity and Social Hierarchy of Hallyu Fans. The Journal for Undergraduate Ethnography, 9(March), 65-81. https://doi.org/10.15273/ jue.v9i1.8885

Rhee, Y. C., Wong, J., \& Kim, Y. (2016). Becoming Sport Fans: Relative Deprivation and Social Identity. International Journal of Business Administration, 8(1), 118. https://doi.org/ 10.5430/ijba.v8n1p118

Ryff, C. (1989). Happiness is everything, or is it? Explorations on the meaning of psychological well-being. Journal of Personality and Social Psychology, 57(6), 1069-1081. https://doi.org/https://doi.org/10.1037/0022-3514.57.6.1069

Seoulbeats. (2012). K-pop and escaping real life. Retrieved from https://seoulbeats.com/2012/ 10/k-pop-and-escaping-real-life/

Soheili, K. (2019). Grueling gym routines, restrictive diets, and no dating: K-pop stars tell us about the dark side of their industry. Insider. Retrieved from https://www.insider.com/kpopdark-side-gym-diet-dating-great-guys-crayon-pop-2019-10

Stever, G. S. (2009). Parasocial and Social Interaction with Celebrities Classification of Media Fans. Journal of Media Psychology Theories Methods and Applications, 14(3).

Thomas, P. A. (2018). I Wanna Wrock! The World of Harry Potter-Inspired "Wizard Rock” and Its Fandom. McFarland \& Co.

Tinaliga, B. (2018). “At War for OPPA and Identity ": Competitive Performativity among Korean-Pop Fandoms. Master's Projects and Capstones, (768).

Tsay-Vogel, M., \& Sanders, M. S. (2017). Fandom and the search for meaning: Examining communal involvement with popular media beyond pleasure. Psychology of Popular Media Culture, 6(1), 32-47. https://doi.org/10.1037/ppm0000085

Um, H. (2014). K-pop on The Global Platform: European Audience Reception and Contexts. Seoul, Republic of Korea. 